\title{
A different perspective on the partial loss of meaning of life
}

\author{
Tam-Tri Le
}

2021 May 22

I write this as a self-conversation. Many ideas in this paper may sound ridiculous to readers.

In this paper, I present my subjective opinions about the partial loss of general meaning attached to life due to the partial experience of death.

The meaning of life is heavily individual, or probably totally individual. Speaking of individuality, the perceivable self is itself a constructed meaning regardless of what constructing it. The issue has been contemplated by countless great and ordinary thinkers. Some others, like myself, would like to add to the side of that chaotic debate a different kind of perspective: non-thinking subjective experience from special states of experiencing. These are some relatively common pathways: meditation, near-deathexperience, psychedelics, dreams, and psychic abilities. Most scientists do not accept this "method of investigation", because yes, they are not scientific, nor investigation, nor method. They are what they are: subjective experiences that can be denied by others but cannot negate the experiencing occurrences themselves.

Personally, I came close to biological death a couple of times and have experienced paranormalities during alternative states of consciousness. Those experiences have no intrinsic meanings. That does not mean I do not attach some meanings to them as from normal cognitive habits. However, without attached values, the experiences cannot be described using languages. For me, they do not have to be. With awareness during those occurrences, I was presented a form of existence (of that world, regardless of my self's involvement) which is devoid of reasons (logical linear causation) but instead holds different, uninterpretable properties when the experiencing happens. In other words, it is the "interaction" between two subjects, or even between two objects, as opposed to subject against object. Of course, any metaphor or attempt to explain here is incorrect.

But something does not have to be understood to have influence. The more I got into contact with the otherworldly existence, the more I lose some attached meanings deemed normal in a person. I do not become generally apathetic, but I do become apathetic toward many things which people are expected to pay a great deal of consideration. In the opposite direction, I find the process of doing art to be more emotional and aesthetic, yet the products to be much less significant (that I do not care if they disappeared). In some points in the past, the unordinary expressions of my thoughts have caused confusion and 
emotional pain to my friends and family members. Thus, I adjusted my behaviors according to the softer social norms.

While to me life is gradually losing meanings, the process does not really affect my human functions in society, or so I think. I can still find joy and sorrow both in active scientific or philosophical investigations, and in many mundane or animalistic aspects of life. It is similar to enjoying or detesting the ups and downs of a dream, lucid or not. I do not long for the existence after death, for it is but another environment - only with very different properties. I also find it vague for me addressing myself or addressing life, for I have subjectively known several times that it is just as fine without. And so, it is to me equally acceptable to just leave this current existence for whatever reasons, because there are no reasons after the transition. I do not consider this way of thinking suicidal or as symptoms of depressive disorder in one way or another.

Discussions on what being beyond language only create misinterpretations, starting from my own. Normally people do not strictly discuss about breathing in order to breathe; and people still find oxygen to be very refreshing, or they do not care at all regardless. Obviously, this paper sounds ridiculous, even to me, for I am thinking about it. If you are curious about the alternative perspectives on the meaning of life, try experiencing the alternative experiences before arguing, for you may find that there is nothing to argue about, at all. Meditation is relatively a safe path compared to the others which might be dangerous or illegal. However, humans still have the natural limitations of being humans, thus such experiences are partial - like a peek through a hole on the wall. But the "when" factor is insignificant, for when "time" runs out each human will die and know. 